\title{
FAKTOR-FAKTOR YANG MEMENGARUHI TERJADINYA INSOMNIA PADA LANSIA DI SAMANHUDI KELURAHAN ESTATE KECAMATAN BINJAI SELATAN TAHUN 2016
}

\author{
Factors that Influence the Happening of Insomnia in Elderly \\ in Samanhudi Estate Binjai South District in 2016
}

\author{
Hasan Basri Nasution ${ }^{1}$ \\ ${ }^{1}$ Dosen Akademi Keperawatan Sehat Binjai \\ E-mail: hasanbasrinasution12@yahoo.com
}

\begin{abstract}
Abstrak
Penuaan merupakan normal, dengan perubahan fisik dan tingkah laku yang dapat diramalkan yang terjadi pada semua orang pada saat mereka mencapai usia tahap perkembangan kronologis tertentu. Pengambilan sampel dalam penelitian ini menggunakan total sampling dilakukan dengan mengambil sampel atau responden yang kebetulan ada di Di Samanhudi Kelurahan Estate Kecamatan Binjai Selatan. sebanyak 30 orang. Dalam penulisan ini penulis menggunakan pengumpulan data kuisioner/angket dengan skala Guttman. Hasil penelitian dari 30 responden berumur 60-65 tahun sebanyak 12 orang (40\%), 66-70 tahun sebanyak 10 orang (33\%), 71-75 tahun sebanyak 8 orang (27\%), dari 30 responden berpendidikan SD sebayak 16 orang (53\%), SMP sebanyak 7 orang (23\%), SMA sebanyak 5 orang (17\%), perguruan tinggi sebanyak 2 orang (7\%), dari 30 responden faktor-faktor penyebab insomnia berdasarkan faktor psikologi sebanyak 12 orang $(40 \%)$ berdasarkan problem psikiatri sebanyak 2 orang (7\%) berdasarkan sakit fisik sebanyak 3 orang (10\%) berdasarkan faktor lingkungan sebanyak 2 orang (7\%) berdasarkan gaya hidup sebanyak 2 orang $(7 \%)$ berdasarkan tidur siang berlebihan sebanyak 9 orang $(30 \%)$. Diharapkan para lansia agar mengembangkan kebiasaan tidur pada waktu malam hari dan berusaha untuk mengurangi stres dan depresi, melakukan gerak badan atau olah raga setiap hari agar terciptanya badan dan jiwa yang sehat, tidak merokok dan meminum alkohol, atau kopi pada malam hari, rutin pemeriksaan kesehatan terutama dibalai kesehatan terdekat, semoga dapat mengurangi dan memperendah angka peningkatan insomnia pada lansia.
\end{abstract}

Kata kunci : Faktor-faktor yang mempengaruhi insomnia pada lansia

\begin{abstract}
Aging is normal, with physical changes and predictable behavior that occurs in all people when they reach the age of a certain stage of chronological development. Sampling in this study using total sampling was done by taking samples or respondents who happened to be in Di Samanhudi Estate Village, South Binjai District. as many as 30 people. In this paper the author uses questionnaire / questionnaire data collection with Guttman scale. The results of the study from 30 respondents aged 60-65 years as many as 12 people (40\%), 66-70 years as many as 10 people (33\%), 71-75 years as many as 8 people (27\%), from 30 respondents with elementary education as 16 people (53\%), SMP as many as 7 people (23\%), SMA as many as 5 people (17\%), colleges as many as 2 people $(7 \%)$, from 30 respondents the factors that cause insomnia based on psychological factors as many as 12 people $(40 \%)$ based on psychiatric problems as many as 2 people $(7 \%)$ based on physical illness as many as 3 people $(10 \%)$ based on environmental factors as many as 2 people $(7 \%)$ based on lifestyle of 2 people (7\%) based on excessive napping of 9 people $(30 \%)$. It is hoped that the elderly will develop the habit of sleeping at night and try to reduce stress and depression, exercise or exercise every day to create a healthy body and soul, not smoke and drink alcohol, or coffee at night, regular health checks especially near the nearest health, hopefully it can reduce and lower the rate of increase in insomnia in the elderly.
\end{abstract}

Keywords: Factors that affect insomnia in the elderly

\section{PENDAHULUAN}

Saat ini, diseluruh dunia jumlah orang lanjut usia diperirakan ada 500 juta dan usia rata-rata 60 tahun yang diperkirakan pada tahun 2025 kan mencapai 1,2 milyar. Di Negara maju seperti amerika serikat bertambahnya orang lanjut usia diperkirakan 1.000 orang perhari pada tahun 1985 diperkirakan $50 \%$ dari penduduk berusia 50 tahun sehingga istilah baby boom pada masa lalu berganti menjadi "ledakan 
penduduk lanjut usia" (lansia) (Padila, 2014).

Dengan bertambahnya usia, waktu tidur seseorang cendrung berkurang. Semakin banyak umur, waktu terjaga semakin banyak. Pola terbangun dini hari lebih sering ditemukan pada usia lanjut. Beberapa orang tertidur secara normal, tetapi terbangun beberapa jam kemudian dan sulit untuk tertidur kembali, kadang mereka tidur dengan keadaan gelisah dan merasa belum puas tidur, terbangun pada dini hari, pada usia berapapun, merupakan tanda depresi. orang yang memiliki pola tidur terganggu dapat mengalami irama tidur yang terbaik, mereka tertidur bukan pada waktunya tidur dan bangun pada saatnya tidur (Susilo \& Wulandari, 2011).

Setelah orang mengalami masa lansia umumnya mulai dihinggapi adanya kondisi fisik yang barsifat patologis berganda (multiple pathologi), misalnya tenaga berkurang, enerji menurun, kulit makin keriput, gigi makin rontok, tulang makin rapuh, Secara umum kondisi fisik seseorang yang sudah memasuki masa lansia mengalami penurunan secara berlipat ganda. Hal ini semua dapat menimbulkan gangguan atau kelainan fungsi fisik, psikologik, maupun sosial, yang selanjutnya dapat menyebabkan suatu ketergantungan kepada orang lain (Padila, 2014).

Menurut WHO dan Undang-Undang NO 13 Tahun 1998 tentang kesejahteraan lanjut usia pada pasal 1 ayat 2 yang menyebutkan bahwa umur 60 tahun adalah usia permulaan tua. Menua bukanlah suatu penyakit, akan tetapi merupakan proses yang berangsur-angsur mengakibatkan perubahan yang kumulatif, merupakan proses menurunnya daya tahan tubuh dalam menghadapi rangsangan dari dalam dan luar tubuh yang berahir dengan kematian (Padila, 2014).

Orang-orang yang tidur kurang dari 6 jam atau lebih dari 8 jam memiliki tingkat kematian lebih tinggi, tidur selama 8,5 jam atau lebih setiap malam dapat meningkatkan angka kematian sebesar 15 persen, artinya, tidur harus dilakukan setiap hari dalam porsi yang cukup untuk menjaga kesehatan yang meningkatkan harapan hidup, insomnia atau tidur kurang dari 3,5 jam (perempuan) dan
4,5 jam (laki-laki) juga dapat menyebabkan kenaikan sebesar 15 persen tingkat kematian, setelah mngontrol durasi tidur insomnia, menggunakan pil tidur juga berkaitan dengan peningkatan angka kematian (Susilo \& Wulandari, 2011).

Menua (menjadi tua) adalah suatu proses menghilangnya secara berlahan-lahan kemampuan jaringan untuk mempertahankan fungsi normalnya sehingga hingga dapat bertahan terhadap infeksi dan memperbaiki kerusakan yang di derita (Constantanides, 1994) ini merupakan roses yang terus-menerus (berlanjut) secara alami, ini dimulai sejak lahir dan umumnya dialami pada semua mahluk hidup (Bandiyah, 2009).

Dengan adanya peningkatan insomnia seiring bertambahnya usia, maka peneliti tertarik untuk mengetahui lebih dalam lagi mengenai "Faktor-Faktor yang Mempengaruhi Terjadinya Insomnia pada Lansia" di Samanhudi Kelurahan Binjai Estate Kecamatan Binjai Selatan.

Berdasarkan survey pendahululuan yang dilakukan peneliti di Samanhudi Kelurahan Binjai Estate Kecamatan Binjai Selatan, terdapat lansia berumur 60-65 tahun sebanyak 12 orang (40\%), 66-70 tahun sebanyak 10 orang (33\%), 71-75 tahun sebanyak 8 orang (27\%), total 30 (100\%).

Berdasarkan uraian di atas maka penulis tertarik untuk penelitian yang berjudul "Faktor-Faktor yang Mempengaruhi Terjadinya Insomnia pada Lansia" di Samanhudi Kelurahan Binjai Estate Kecamatan Binjai Selatan.

\section{METODE}

Jenis penelitian ini adalah bersifat deskriptif bertujuan untuk menerangkan atau manggambarkan masalah penelitian yang terjadi berdasarkan karakteristik, tempat, waktu, umur, jenis kelamin, sosial, ekonomi, pekerjaan status perkawinan, cara hidup (pola hidup) dan lain-lain (hidayat, 2007).

Penelitian ini dilakukan, karena ditemukan tingginya jumlah kasus penyakit insomnia yang ada di Samanhudi Kelurahan Binjai Estate Kecamatan Binjai Selatan Sesuai dengan data yang diperoleh tahun 2016 dan dekatnya lokasi penelitian dengan asrama sehingga memudahkan peneliti untuk meminimalkan biaya penelitian. 
Penelitian ini dilakukan pada bulan januari sampai pebruari 2016. Dari survey awal, pengambilan data, proposal, sampai dengan sidang penelitian.

Populasi adalah wilayah generalisasi yang terjadi diatas: objek dan subjek yang mempunyai kuantitas dan karaktristik tertentu yang ditetepkan oleh peneliti untuk mempelajari dan kemudian ditarik kesimpulannya (Hidayat, 2007).

Populasi dalam penelitian ini adalah seluruh lansia yang mengalami insomnia di Samanhudi Kelurahan Binjai Estate Kecamatan Binjai Selatan Tahun 2016 sebanyak 30 lansia.

Sampel merupakan bagaikan populasi yang akan di teliti atau sebagian jumlah dari karaktristik yag dimiliki oleh populasi (Hidayat, 2007).

Sampling yang digunakan adalah total sampling, yaitu semua populasi dijadikan sebagai sampel, Sampel dalam penelitian ini adalah lansia yang mengalami insomnia atau sebagian dari populasi, yaitu sebanyak 30 lansia.

Cara meneliti untuk mengumpulkan data dalam penelitian, sebelum melakukan pengumpulan data, perlu dilihat alat ukur pengumpulan data agar dapat memperkuat hasil penelitian. Alat ukur pengumpulan data tersebut antara lain dapat berupa koensioner/ angka, observasi, wawancara, atau gabungan ketiganya (Hidayat, 2007).

Alat ukur pengumpulan data pada penelitian ini adalah kuensioner. Dalam penelitian ini menjelaskan kepada responden tentang tujuan, manfaat dan proses pengisian kuisioner sebelumnya menyatakan kesediaan menjadi responden, calon resonden yang bersedia diminta untuk menanda tangani lembar perserujuan yang disediakan. Responden diberikan angket atau kuensioner yang akan diisi dan selanjutnya data dikumpulkan untuk dianalisa.

Dalam penelitian ini penulis menggunakan angket tertutup dengan 18 pernyataan yang akan diberikan kepada 30 responden.

Untuk mengukur data dalam penelitian ini menggunakan skala gutman skala ini dapat digunakan untuk mengukur sikap, pendapat, persepsi, seseorang tentang gejala atau malah yang ada di masyarakat atau dialaminya. Beberapa bentuk pernyataan atau pernyataan yang masuk dalam kategori guttman adalah dengan memberikan jawaban yang tegas seperti ya dan tidak.

1. Bila pertanyaan jawaban benar oleh responden ya $=1$

2. Bila pertanyaan jawaban tidak oleh responden tidak $=0$

3. Pengolahan data secara manual pada saat ini memang jarang dilakukan, sudah ketinggalan zaman. Namun dalam keterbatasan - keterbatasan sarana dan prasarana atau kalau ada data yang tidak terlalu besar, pengelohan data secara manual masih diperlukan (Notoadmodjo, 2010).

4. Dalam proses pengolahan data secara manual terdapat langkah langkah yang harus di tempuh diantaranya :

5. Editing, merupakan kegiatan untuk pengecekan dan perbaikan isian formulir atau kuisioner. Editing dapat dilakukan pada tahap pengumpulan data atau setelah data terkumpul.

6. Coding, adalah mengubah dataa bentuk kalimat atau huruf menjadi data angka atau bilangan. Coding atau pemberian kode ini sangat berguna dalam memasukkan data (Entry).

7. Memasukkan Data (Entry), yakni jawaban - jawaban dari masing masing responden dalam bentuk kode (angka atau huruf), dimasukkan kedalaam masker tabel atau data base komputer, kemudian membuat distribusi frekuensi sederhana atau bisa juga dengan membuat tabel kontigensi.

8. Pembersihan Data (cleaning), Apaabila semua data dari semua sumber data atau responden selesai dimasukkan, perlu cek kembali untuk melihat kemungkinan adanya kesalahan kode, ketidak lengkapan dan sebagainya. 
HASIL PENELITIAN

Karakteristik Umum Responden

1. Berdasarkan Umur

Tabel 1. Kerakteristik Faktor-Faktor Penyebab Insomnia Berdasarkan Umur Di Samanhudi Kelurahan Estate Kecamatan Binjai selatan Tahun 2016

\begin{tabular}{cccc}
\hline No & Usia & Frekuensi & Persentase (\%) \\
\hline 1 & $60-65$ & 12 & 40 \\
2 & $66-70$ & 10 & 33 \\
3 & $71-75$ & 8 & 27 \\
\hline & Total & $\mathbf{3 0}$ & $\mathbf{1 0 0}$ \\
\hline
\end{tabular}

Berdasarkan tabel di atas dilihat bahwa dari 30 responden berumur 60-65 tahun sebanyak 12 orang (40\%), 66-70 tahun sebanyak 10 orang (33\%), 71-75 tahun sebanyak 8 orang $(27 \%)$.

Tabel 2. Karakteristik Faktor-Faktor Penyebab Insomnia Berdasarkan Tingkat Pendidikan Di Samanhudi Kelurahan Estate Kecamatan Binjai Selatan Tahun 2016

\begin{tabular}{cccc}
\hline No & Tingkat Pendidikan & Frekuensi & Persentase (\%) \\
\hline 1 & SD & 16 & 53 \\
2 & SMP & 7 & 23 \\
3 & SMA & 5 & 17 \\
4 & Perguruan Tinggi & 2 & 7 \\
\hline & Total & $\mathbf{3 0}$ & $\mathbf{1 0 0}$ \\
\hline
\end{tabular}

Berdasarkan tabel di atas dilihat bahwa dari 30 responden berpendidikan SD sebayak 16 orang (53\%), SMP sebanyak 7 orang (23\%), SMA sebanyak 5 orang (17\%), perguruan tinggi sebanyak 2 orang $(7 \%)$.

Table 3. Distribusi Frekuensi Responden Berdasarkan Faktor Psikologi Di Samanhudi Kelurahan Estate Kecamatan Binjai Selatan Tahun 2016

\begin{tabular}{ccc}
\hline Kategori & Frekuensi & Persentase (\%) \\
\hline Dominan & 12 & 40 \\
Tidak Dominan & 18 & 60 \\
\hline Total & $\mathbf{3 0}$ & $\mathbf{1 0 0}$ \\
\hline
\end{tabular}

Berdasarkan tabel di atas dilihat bahwa dari 30 responden faktor penyebab insomnia berdasarkan faktor psikologi dominan sebanyak 12 orang (40\%), dan tidak dominan sebanyak 18 orang $(60 \%)$.

Tabel 4. Distribusi Frekuensi Responden Berdasarkan Problem Psikiatri Di Samanhudi Kelurahan Estate Kecamatan Binjai Selatan Tahun 2016

\begin{tabular}{ccc}
\hline Kategori & Frekuensi & Persentase (\%) \\
\hline Dominan & 2 & 7 \\
Tidak Dominan & 28 & 93 \\
\hline Total & $\mathbf{3 0}$ & $\mathbf{1 0 0}$ \\
\hline
\end{tabular}


Berdasarkan tabel di atas dilihat bahwa dari 30 responden faktor penyebab insomnia berdasarkan problem psikiatri dominan sebanyak 2 orang (7\%) dan tidak dominan sebanyak 28 orang $(93 \%)$.

Table 5. Distribusi Frekuensi Responden Berdasarkan Sakit Fisik Di Samanhudi Kelurahan Estate Kecamatan Binjai Selatan Tahun 2016

\begin{tabular}{ccc}
\hline Kategori & Frekuensi & Persentase (\%) \\
\hline Dominan & 3 & 10 \\
Tidak Dominan & 27 & 90 \\
\hline Total & $\mathbf{3 0}$ & $\mathbf{1 0 0}$ \\
\hline
\end{tabular}

Berdasarkan tabel di atas dilihat bahwa dari 30 responden faktor penyebab insomnia berdasarkan sakit fisik dominan sebanyak 3 orang (10\%) dan tidak dominan sebanyak 27 orang $(90 \%)$.

Table 6. Distribusi Frekuensi Responden Berdasarkan Faktor Lingkungan Di Samanhudi Kelurahan Estate Kecamatan Binjai Selatan Tahun 2016

\begin{tabular}{ccc}
\hline Kategori & Frekuensi & Persentase (\%) \\
\hline Dominan & 2 & 7 \\
Tidak Dominan & 28 & 93 \\
\hline Total & $\mathbf{3 0}$ & $\mathbf{1 0 0}$ \\
\hline
\end{tabular}

Berdasarkan tabel di atas dilihat bahwa dari 30 responden faktor penyabab insomnia bedasarkan faktor lingkungan dominan sebanyak 2 orang $(7 \%)$ dan tidak dominan sebanyak 28 orang (93\%).

Table 7. Distribusi Frekuensi Responden Berdasarkan Gaya Hidup Di Samanhudi Kelurahan Estate Kecamatan Binjai Selatan Tahun 2016

\begin{tabular}{ccc}
\hline Kategori & Frekuensi & Persentase (\%) \\
\hline Dominan & 2 & 7 \\
Tidak Dominan & 28 & 93 \\
\hline Total & $\mathbf{3 0}$ & $\mathbf{1 0 0}$ \\
\hline
\end{tabular}

Berdasarkan tabel di atas dilihat bahwa dari 30 responden faktor penyabab insomnia berdasarkan gaya hidup dominan sebanyak 2 orang (7\%) dan tidak dominan sebanyak 28 orang $(93 \%)$.

Tabel 8. Distribusi Frekuensi Responden Tidur Siang Berlebihan Di Samanhudi Kelurahan Estate Kecamatan Binjai Selatan Tahun 2016

\begin{tabular}{ccc}
\hline Kategori & Frekuensi & Persentase (\%) \\
\hline Dominan & 9 & 30 \\
Tidak Dominan & 21 & 70 \\
\hline Total & 30 & 100 \\
\hline
\end{tabular}


PEMBAHASAN

\section{Karakteristik Umum Responden}

Dalam penelitian ini yang menjadi sampel adalah lansia yang berada Di Samanhudi Kelurahan Binjai Estate Kecamatan Binjai Selatan Tahun 2016 sebanyak 30 responden $100 \%$.

\section{Umur}

Karakteristik berdasarkan usia Di Samanhudi Kelurahan Binjai Estate Kecamatan Binjai Tahun 2016 dari 30 responden $(100 \%)$ mayoritas berumur 60-65 tahun sebanyak 12 orang (40\%), 66-70 tahun sebanyak 10 orang (33\%), 71-75 tahun sebanyak 8 orang (27\%).

\section{Pendidikan}

Karakteristik berdasarkan pendidikan Di Samanhudi Kelurahan Binjai Estate Kecamatan Binjai Tahun 2016 dari 30 responden (100\%) mayoritas berpendidikan SD sebayak 16 orang (53\%), SMP sebanyak 7 orang (23\%), SMA sebanyak 5 orang (17\%), perguruan tinggi sebanyak 2 orang $(7 \%)$. Hal ini membuktikan bahwa tingkat pengetahuan lansia kurang terhadap insomnia. Peneliti berasumsi bahwa dengan pendidikan lansia tersebut SD maka wajar saja pengetahuannya kurang, karena keterbatasan lansia dalam memperoleh informasi. Makin tinggi pendidikan seseorang akan cenderung mendapatkan informasi baik dari orang lain maupun media massa.

(http//id.wikipedia.org/wiki/insomnia)

\section{Berdasarkan Distribusi Frekuensi Responden}

\section{Berdasarkan Faktor Psikologis}

Hal ini membuktikan bahwa stres yang berkepanjangan paling sering menjadi penyebab dari insomnia kronis. Tingkat tuntunan yang tinngi atau keinginan yang tidak tercapai, hingga berita-berita kegagalan sering mamicu terjadinya insomnia transient. Orang-orang yang memiliki masalah-masalah stress, sering kali mengalami insomnia. Berdasarkan hasil penelitian dari 30 responden faktor penyebab insomnia berdasarkan faktor psikologi dimana dominan sebanyak 12 orang $(40 \%)$, dan tidak dominan sebanyak
18 orang (60\%) (Susilo \& Wulandari, 2011).

\section{Berdasarkan Problem psikiatri}

Hal ini membuktikan bahwa perasaan yang berlebihan, neorosa (gangguan jiwa), dangan gangguan psikologi lainnya juga sering menjadi penyebab dari gangguan tidur. berdasarkan hasil penelitian dari 30 responden faktor penyebab insomnia berdasarkan problem psikiatri dimana dominan sebanyak 2 orang (7\%) dan tidak dominan sebanyak 28 orang (93\%) (Susilo \& Wulandari, 2011).

\section{Berdasarkan Sakit Fisik}

Hal ini membuktikan bahwa orang yang mengalami sakit fisik seperti sesak nafas pada orang yang terserang asma, sinusitis, maupun flu yang menyebabkan hidung tersumbat dapat menjadi penyebab gangguan tidur. berdasarkan hasil penelitian dari 30 responden faktor penyebab insomnia berdasarkan sakit fisik dimana dominan sebanyak 3 orang (10\%) dan tidak dominan sebanyak 27 orang (90\%) (Susilo $\&$ Wulandari, 2011).

\section{Berdasarkan Faktor Lingkungan}

Lingkungan berperan besar terhadap terjadinya insomnia seseorang. Lingkngannya yang bising, seperti lingkungan lintasan pesawat terbang, lintasan kereta api, pabrik dengan mesinmesin yang terus beroperasi sepanjang malam atau suara TV yang keras dapat menjadi faktor penyebab sulit tidur. berdasarkan hasil penelitian dari 30 responden faktor penyebab insomnia berdasarkan faktor lingkungan dimana dominan sebanyan 2 orang (7\%) dan tidak dominan sebanyak 28 orang (93\%)

(Susilo \& Wulandari, 2011).

\section{Berdasarkan Gaya Hidup}

Gaya hidup yang tidak sehat juga dapat memicu terjadinya insomnia. Kebiasan mengonsumsi alkohol, rokok, kopi (kafein), obat penurun berat badan, jam kerja tidak teratur, juga dapat menjadi faktor penyebab sulit tidur.berdasarkan hasil penelitian dari 30 responden faktor penyebab insomnia berdasarkan gaya hidup 
dimana dominan sebanyak 2 orang $(7 \%)$ dan tidak dominan sebanyak 28 orang (93\%) (Susilo \& Wulandari, 2011).

\section{Berdasarkan Tidur Siang Berlebihan}

Banyak orang terbiasa dengan tidur siang setiap harinya, mungkin mereka memerlukan istirahat total sekitar 10-30 menit dengan tidur siang. Hal ini bisa disebut normal atau wajar. Mungkin mereka kelelahan bekerja sehingga butuh waktu tidur siang sejenak. Mereka yang tidur berlebihan di siang hari sehingga akhirnya mereka mengalami kesulitan tidur pada malam hari. berdasarkan hasil penelitian dari 30 responden faktor penyebab insomnia berdasarkan tidur siang berlebihan dimana dominan sebanyak 9 orang $(30 \%)$ dan tidak dominan sebanyak 21 orang (70\%) (Susilo \& Wulandari, 2011).

\section{KESIMPULAN}

1. Dari 30 responden berdasarkan kehadiran perkuliahan, Responden memiliki kehadiran perkuliahan negatif/ tidak aktif sebanyak 19 orang $(63,3 \%)$ dan positif/ aktif sebanyak 11 orang $(36,7)$

2. berdasarkan hasil penelitian dari 30 responden faktor penyebab insomnia berdasarkan sakit fisik dimana dominan sebanyak 3 orang (10\%) dan tidak dominan sebanyak 27 orang (90\%).

3. Berdasarkan hasil penelitian dari 30 responden faktor penyebab insomnia berdasarkan faktor psikologi dimana dominan sebanyak 12 orang (40\%), dan tidak dominan sebanyak 18 orang $(60 \%)$

\section{SARAN}

1. Disarankan kepada Lansia memperhatikan pola tidur yang teratur agar terhindar dari berbagai penyakit.

2. Diharapkan bagi Lansia untuk menjalani pola hidup sehat agar bisa terhindar dari insomnia.

3. Bagi peneliti pembaca penelitian diharapkan menambahkan saran yang lebih membangun agar penelitian ini menjadi lebih baik.

\section{DAFTAR PUSTAKA}

Hidayat, A., 2010. Riset Keperawatan dan Teknik Penulisan Ilmiah. Jakarta : Salemba Medika.

Notoatmodjo, S. 2010. Metodologi Penelitian Kesehatan. Jakarta : Rineka Cipta.

Nursalam, 2003. Konsep dan Penerapan Metodologi Penelitian Ilmu Keperawatan. Jakarta : Salemba Medika.

Poerwadarminta, W. 2007. Kamus Umum Bahasa Indonesia. Jakarta: Balai Pustaka.

Purwandari, 2009. Pengaruh Terapi Seni Dalam Menurunkan Tingkat Kecemasan Anak Usia Sekolah Yang Mengalami Hospitalisasi Di Wilayah Kabupaten Banyumas. Thesis. Depok: Universitas Indonesia.

Puspitasari, G. 2008. Hubungan Insomnia Dengan Kualitas Hidup. Thesis. Yogyakarta : Fakultas Kedokteran UMY.

Rafknowledge, 2004. Insomnia dan Gangguan Tidur Lainnya. Jakarta : PT Elex Media Komputindo.

Sugiyono, 2010. Statistik Untuk Penelitian. Bandung: CV. Alfabeta.

Walgito, 2010. Pengantar Psikologi Umum. Yogyakarta: CV. Andi Offset.

Yeriko, M., 2010. Konsep Mahasiswa. http ://Mr.yeriko.com/konsep-mahasiswa. Diakses pada tanggal 5 Juli 2010 